\title{
Comment on "Effectiveness of Naltrexone in the Prevention of Delayed Respiratory Arrest in Opioid-Naive Methadone-Intoxicated Patients"
}

\author{
Abbas Aghabiklooei, ${ }^{1,2}$ Hossein Hassanian-Moghaddam, ${ }^{1}$ and Nasim Zamani $^{1}$ \\ ${ }^{1}$ Toxicological Research Center, Loghman-Hakim Hospital, Department of Clinical Toxicology, Faculty of Medicine, \\ Shahid Beheshti University of Medical Sciences, Kamali Avenue, South Kargar Street, Tehran 13336 35445, Iran \\ ${ }^{2}$ Department of Forensic Medicine, Iran University of Medical Sciences, Tehran 14456 13131, Iran
}

Correspondence should be addressed to Hossein Hassanian-Moghaddam; hassanian@sbmu.ac.ir

Received 25 September 2014; Accepted 30 September 2014

Academic Editor: Hartmut Jaeschke

Copyright (C) 2015 Abbas Aghabiklooei et al. This is an open access article distributed under the Creative Commons Attribution License, which permits unrestricted use, distribution, and reproduction in any medium, provided the original work is properly cited.

We read with interest the comments on our recent paper $[1,2]$. We think that some points should be clarified to your readers as well as the authors of these comments. Our recent study showed that at least 435 out of 1072 patients $(40.5 \%)$ in our center were intentionally or accidentally intoxicated by methadone, of whom 216 (20.2\%) were younger than 12 years and were admitted to the pediatric ward [3].

Therefore, we believe that the applicability of this therapeutic approach is quite noticeable. We agree that some opioid-naive methadone-intoxicated patients may hide their dependency in history taking but naloxone challenge test will reveal it soon. Starting administration of $0.05-0.1 \mathrm{mg}$ naloxone to each patient even in those who claim not to be dependent is recommended. Withdrawal syndrome caused by oral naltrexone in opioid dependents is usually not life threatening except in ischemic heart disease patients as our previous study showed one death among 132 cases (0.8\%) [4]. This fatality is different from long withdrawal precipitated by naltrexone pellet implantation that the authors have mentioned [1]. By the way, we emphasize naloxone challenge test in all patients to prevent withdrawal syndrome.

Although we had no morbidity and mortality in naltrexone group in hospital and in our follow-up clinic, we agree that $50 \mathrm{mg}$ naltrexone may not be enough. The reason why we did not face delayed respiratory depression may be explained by the period of prehospital admission in which methadone half-life had partly passed. This theoretical limitation can be resolved by administration of $150 \mathrm{mg}$ naltrexone to increase its time of effect to 72 hours. Thus, we recommend a naloxone challenge test, giving $50 \mathrm{mg}$ naltrexone if no withdrawal syndrome is observed and giving additional $100 \mathrm{mg}$ naltrexone if the first dose is tolerated.

\section{Conflict of Interests}

The authors declare that there is no conflict of interests regarding the publication of this paper.

\section{References}

[1] B. D. Kessler and R. S. Hoffman, "Comment on "Effectiveness of naltrexone in the prevention of delayed respiratory arrest in opioid-naïve methadone-intoxicated patients"," BioMed Research International, vol. 2014, Article ID 705754, 1 page, 2014.

[2] A. Aghabiklooei, H. Hassanian-Moghaddam, N. Zamani et al., "Effectiveness of naltrexone in the prevention of delayed respiratory arrest in opioid-naive methadone-intoxicated patients," BioMed Research International, vol. 2013, Article ID 903172, 7 pages, 2013. 
[3] S. Shadnia, M. Rahimi, H. Hassanian-Moghaddam, K. Soltaninejad, and A. Noroozi, "Methadone toxicity: comparing tablet and syrup formulations during a decade in an academic poison center of Iran," Clinical Toxicology, vol. 51, no. 8, pp. 777-782, 2013.

[4] H. Hassanian-Moghaddam, S. Afzali, and A. Pooya, "Withdrawal syndrome caused by naltrexone in opioid abusers," Human \& Experimental Toxicology, vol. 33, no. 6, pp. 561-567, 2014. 

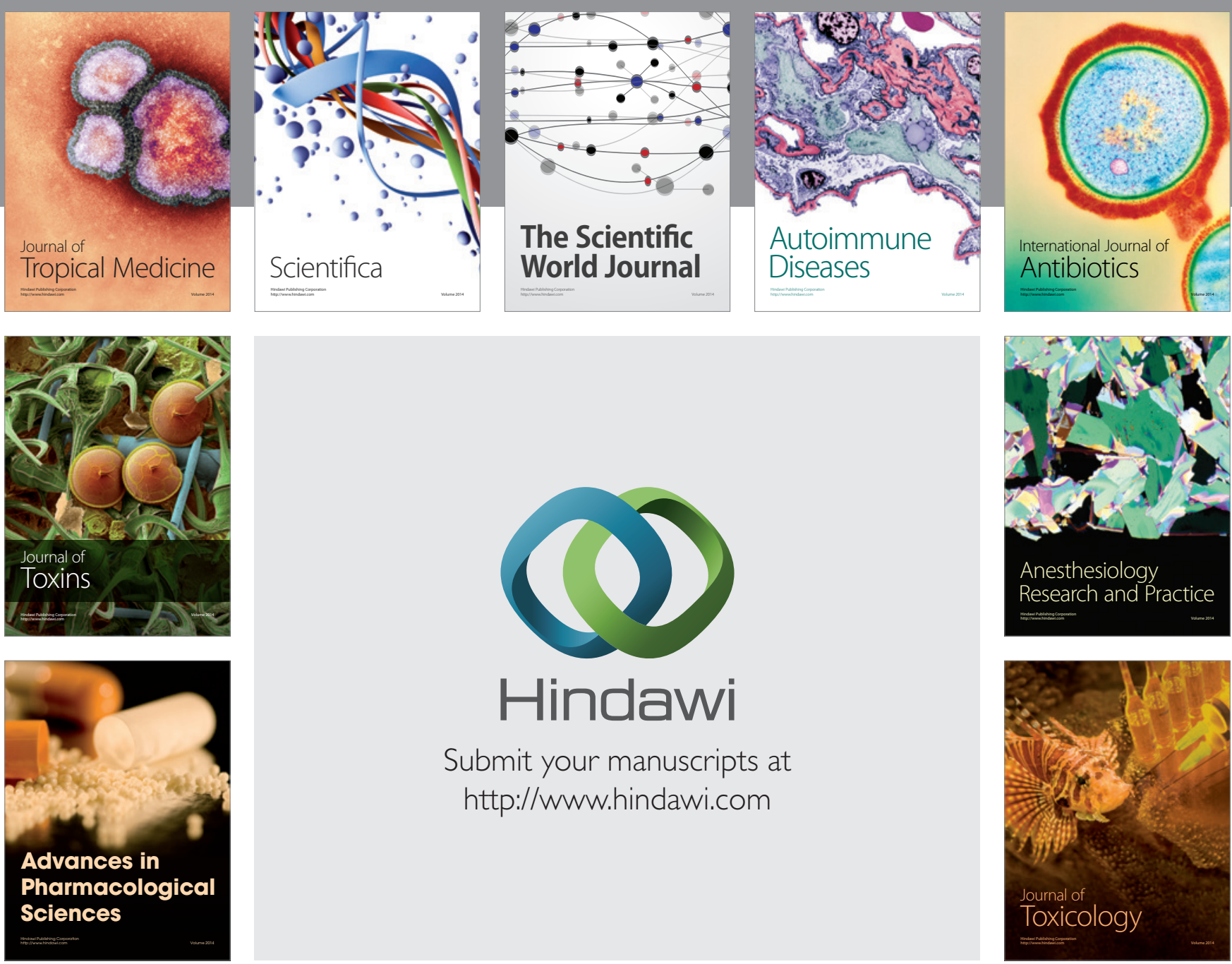

\section{Hindawi}

Submit your manuscripts at

http://www.hindawi.com
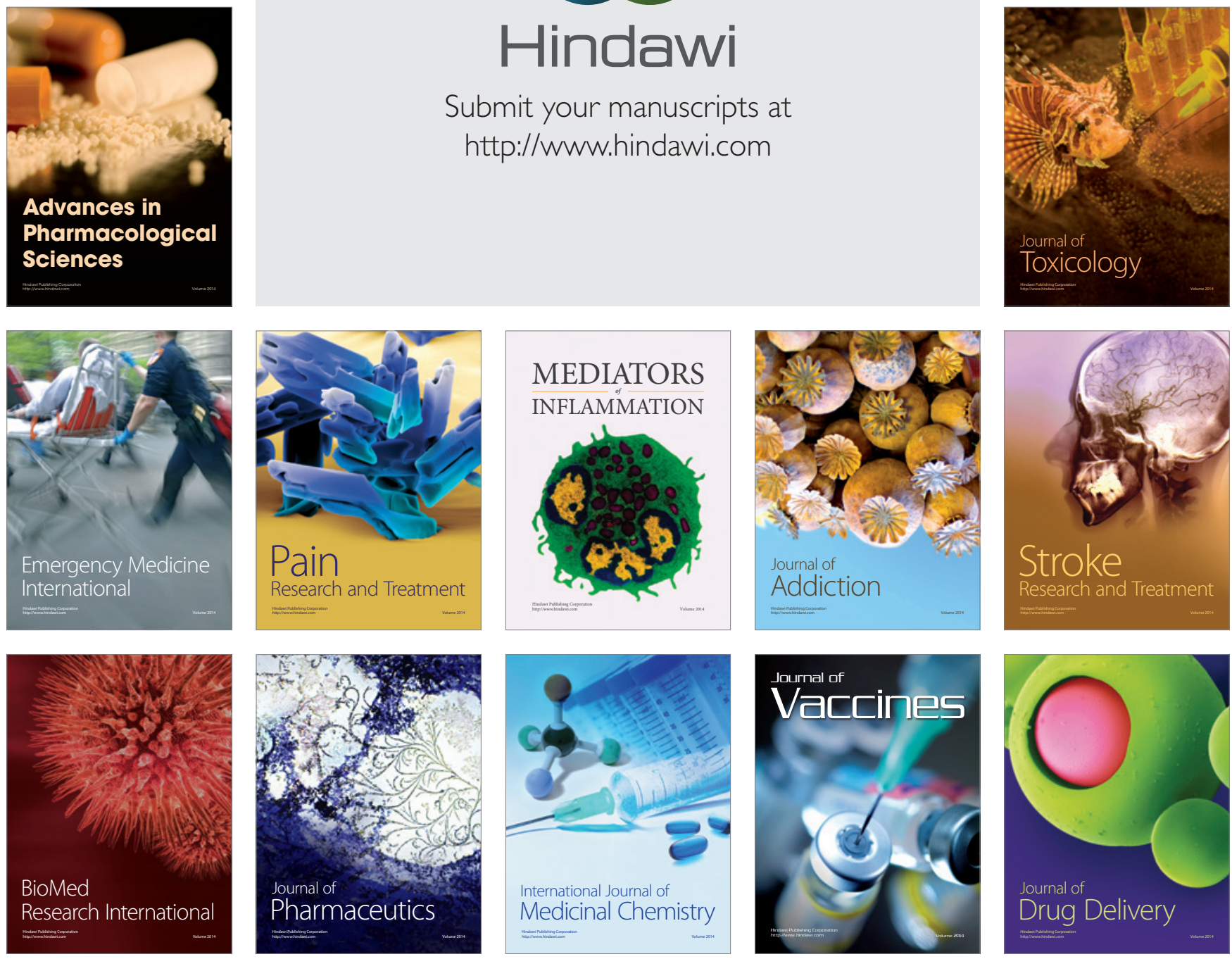